\title{
Boerhaave's syndrome presenting as tension pneumothorax
}

Wilson O C Onyeka, S Jeremy Booth

\begin{abstract}
Boerhaave's syndrome can present initially as a case of tension pneumothorax. Mortality rate with delayed treatment is very high, therefore diagnosis should be made rapidly in the emergency department. Multidisciplinary cooperation, immediate radiological confirmation, prompt aggressive resuscitation, and surgical intervention offer the best chance of survival.
\end{abstract}

(F Accid Emerg Med 1999;16:235-236)

Keywords: Boerhaave's syndrome; tension pneumothorax; multidisciplinary cooperation

\section{Case report}

A 72 year old women was brought to the accident and emergency department of the Chelsea and Westminster Hospital by ambulance in respiratory distress. The previous night she had experienced epigastric pain for about four hours; this culminated in an episode of vomiting 10 hours before presentation that exacerbated her epigastric and retrosternal pain. She became alarmed and called an ambulance when increasing dyspnoea supervened.

She was quickly assessed in the resuscitation room and found to be in profound respiratory distress and peripheral vascular collapse. Her respiratory rate was 30 breaths/min, pulse rate 120 beats/min, thready but regular, temperature $36^{\circ} \mathrm{C}$, oxygen saturation on $15 \mathrm{l} / \mathrm{min}$ via a rebreathing mask $93.2 \%$, and blood pressure 90/50 $\mathrm{mm} \mathrm{Hg}$.

Accepted 11 February 1999

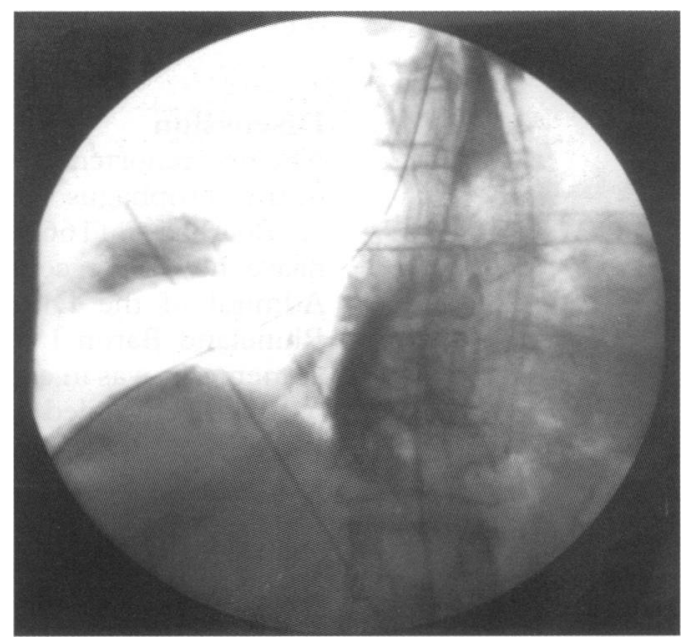

Figure 2 Still fluoroscopy of Gastromiro swallow of patient showing spillage from lower oesophageal tear into the pleural cavity.

Chest examination, arterial blood gas analysis, and electrocardiography were done simultaneously revealing left tracheal deviation, surgical emphysema in the neck, hyper-resonant percussion note, absent breath sounds on the right hemithorax, metabolic acidosis, and sinus tachycardia.

A diagnosis of tension pneumothorax was made and the right hemithorax decompressed immediately with a size $14 \mathrm{G}$ special chest aspiration trochar inserted into the second intercostal space mid-clavicular line. This was followed by aspiration via a three way stopcock that yielded about $500 \mathrm{ml}$ of air. Consequently, her dyspnoea improved significantly allowing a quick mobile post-aspiration chest radiograph (fig 1), which showed $50 \%$ right hydropneumothorax, pneumomediastinum, and surgical emphysema in the neck.

The diagnosis of spontaneous rupture of the oesophagus (Boerhaave's syndrome), complicated by tension pneumothorax, was then made.

Her resuscitation was continued with intravenous infusion of colloids and under water seal pleural drainage with a size $28 \mathrm{ch}(9.3 \mathrm{~mm}$ in diameter) tube inserted into the fifth intercostal space mid-axillary line. This instantly drained about $200 \mathrm{ml}$ of bile stained fluid containing food debris with a $\mathrm{pH}$ of 6.0.

At this stage the surgeons, radiologists, and anaesthetists were immediately involved. She was fasted, had nasogastric intubation with suction, intravenous antibiotics (cefuroxime $1500 \mathrm{mg}$ and metronidazole $500 \mathrm{mg}$ ), and urethral catheterisation. Central venous pressure monitoring was started and an arterial line inserted. 
After a rapid confirmation of right lower linear oesophageal rupture by Gastromiro (E Merck Pharmaceuticals) swallow (fig 2), she underwent thoracotomy for mediastinal lavage and closure of a $3 \mathrm{~cm}$ friable linear lower third oesophageal rupture within five hours of presentation.

Postoperatively she was nursed in the intensive therapy unit. She did well for the first three days but subsequently was overwhelmed by sepsis and died on the 11 th postoperative day.

\section{Discussion}

The first reported case of spontaneous rupture of the oesophagus was by the Dutch physician $\mathrm{H}$ Boerhaave (1668-1738) in $1724 .^{1}$ Boerhaave had been consulted about the Grand Admiral of the Dutch Fleet and Prefect of Rhineland Baron J Van Wassenaer who, after autoemesis, was in excruciating upper abdominal pain. He failed to respond to any of the treatments of the day and died undiagnosed, but Boerhaave conducted a postmortem examination that revealed the rent in the oesophagus and the contents of a previous meal and fluid in the chest.

This classic description made the syndrome more recognisable and it continued to be reported around the world in the intervening centuries-as a postmortem pathological curiosity as it was almost always fatal ${ }^{2}$ - until the first successful drainage by Frink in 1941 and the first successful closure by Barrett in 1947 . This syndrome contrasts with Mallory-Weiss syndrome where there is a linear tear of the oesophagus after prolonged vomiting that results in haematemesis.

Typically Boerhaave's syndrome presents as a case of sudden excruciating upper abdominal and central chest pain after a bout of forceful vomiting, subsequently progressing to dyspnoea and shock.

Oesophageal rupture occurs due to a sudden rise in intraluminal pressure during vomiting when the cricopharyngeus muscles contract against a closed pyloric sphincter. In cadaverous studies the pressure was found to be in the region of $2.25 \mathrm{~kg} / \mathrm{in}^{2}(34.88 \mathrm{kPa})$ and even less in the diseased oesophagus. ${ }^{34}$ Antecedent oesophageal disease is almost always absent. Males out number females in a ratio of 5:1. The lesion is most common in the fifth and sixth decades of life. The posterolateral aspect of the left side of the oesophagus is most commonly involved ( $75 \%-90 \%$ of cases), it can be bilateral in $5 \%-10 \%,{ }^{56}$ or rarely as in this case on the right.

During this event the parietal pleura may rupture simultaneously, leading to immediate communication between the oesophagus and pleural cavity. Alternatively, the parietal pleura becomes breached because of chemical and enzymatic actions of the gastric juices. The initial result of the chemical contamination of the mediastinum is chemical mediastinitis. This results also in mediastinal splinting and contributes to the shock experienced. Subsequently bacterial mediastinitis, empyema thoracis, and sepsis syndrome supervene.
Hydropneumothorax results from direct leakage of fluid and air from the lower oesophagus into the pleural cavity. If air leaks into the pleural cavity during inspiration and fails to escape during expiration, tension pneumothorax develops with its life threatening cardiorespiratory embarrassment (as in this case). Though this extremely rare complication is recognised in the literature as a possible cause of respiratory impairment in Boerhaave's syndrome, ${ }^{7}$ no similar case, as far as we know, has been reported.

Clinically, this condition should be considered in cases of pneumothorax or chest pain if early diagnosis is not to be missed for as $S$ Weiss (1898-1942) said, "A diagnosis is easy, as long as you think of it". When a patient is misdiagnosed or treatment is delayed, as is commonly the case, death inevitably results. It is therefore essential that the diagnosis is rapidly made in the emergency department by good history taking, a physical examination, and radiological investigations. Once considered, multidisciplinary cooperation between emergency physicians, anaesthetists, radiologists, and surgeons from the outset is paramount.

The mainstay of diagnosis of oesophageal perforation is a simple chest radiograph, which is $88 \%$ sensitive. ${ }^{8}$ As in this case, it may show pneumomediastinum, subcutaneous emphysema, and hydropneumothorax. A contrast study of the oesophagus using Gastrograffin (Schering Healthcare) swallow (Gastromiro used in this hospital is iso-osmolar with plasma and causes less pulmonary oedema if aspirated) defines the anatomical location and size of the perforation. Other investigative methods, suitable in some cases, are contrast computed tomography studies of the chest and oesophagoscopy.

Except in moribund cases or in those with a small perforation and little mediastinal contamination, all patients should undergo immediate surgery as this offers the best chance of survival and reduces mortality to $35 \%{ }^{9}$

Conflict of interest: none.

Funding: none.

1 Boerhaave H. Atrocis, mec descripti pruis, morbi historia Secundum Medical artis leges Conscipta, Lugduni Bartavorum, Boutesteniana, 1724.

2 Bruno MS, Grier WRN, Ober WB. Spontaneous laceration and rupture of oesophagus and stomach. Arch Intern Med and rupture of oeso

3 Macler SA. Spontaneous rupture of oesophagus: an experiment and clinical study. Surg Gynaecol Obstet 1952;95:34556.

4 Derrick JR, Harrison WH, Howard HM. Factors predisposing to spontaneous perforation of the oesophagus. Surgery 1958;43:489-9.

5 Curci JJ, Horman MJ. Boerhaave's syndrome: the importance of early diagnosis and treatment. Ann Surg importance of

6 Ghahremani GG. Radiological evaluation of suspected gastrointestinal perforations. Radiol Clin North Am 1993; 31:1219-34.

7 Janjua KJ. Boerhaave's syndrome. Postgrad Med $\mathcal{~} 1997 ; 73$ 265-70.

8 Han SY, McElvein RB, Aldrete JS, et al. Perforation of the oesophagus, correlation of site and cause with plain film findings. $A \mathscr{F} R$ 1985, 145:537-40.

9 Derbes VJ, Mitchell RE. Rupture of the oesophagus. Surgery 1956;39:688, 865 